
\title{
Research S Surate \\ Optimization of Tool Geometric Parameters For a Small Fluteless Forming Tap (FFT)
}

\section{Ming-Chang Wu}

Lunghwa University of Science and Technology

Wei-Rong Jian

National Central University

\section{Ling-Sheng Hsu}

He Zuan Machine Co., Ltd.

chung-chen Tsao ( $\nabla$ aetcc@mail.Ihu.edu.tw)

Lunghwa University of Science and Technology

\section{Research Article}

Keywords: Fluteless forming tap, Tapping, 7075-T6 aluminum alloy, Thread filling rate, Torque

Posted Date: October 22nd, 2021

DOI: https://doi.org/10.21203/rs.3.rs-997301/v1

License: (c) (1) This work is licensed under a Creative Commons Attribution 4.0 International License. Read Full License 


\title{
Optimization of tool geometric parameters for a small fluteless
}

\section{forming tap (FFT)}

\author{
Ming-Chang $\mathrm{Wu}^{1, * *}$, Wei-Rong $\mathrm{Jian}^{2}$, Ling-Sheng $\mathrm{Hsu}^{3}$ and Chung-Chen Tsao ${ }^{1, * *}$
}

${ }^{1}$ Department of Mechanical Engineering, Lunghwa University of Science and Technology, Taoyuan 33306, Taiwan, ROC

${ }^{2}$ Department of Mechanical Engineering, National Central University, Taoyuan 32054, Taiwan, ROC

${ }^{3}$ He Zuan Machine Co., Ltd., Hsinchu 30272, Taiwan, ROC

${ }^{* *}$ Correspondence authors:

$$
\begin{aligned}
& \text { AA021@mail.lhu.edu.tw(M.-C.Wu) } \\
& \text { aetcc@mail.lhu.edu.tw (C.-C.Tsao) } \\
& \text { Fax: +886-2-82096865 }
\end{aligned}
$$

\begin{abstract}
A small blind internal thread (SBIT) is used to firmly fasten some functional components to the cover of $3 \mathrm{C}$ electronic products. The small internal thread is made in a blind hole using a fluteless forming tap (FFT) that does not produce chips. However, the four geometric parameters (tool width $(W)$, tooth root diameter $\left(D_{2}\right)$, front-end diameter $\left(D_{f}\right)$ and tooth angle $\left.(\theta)\right)$ for the FFT affect the thread filling rate $(f)$ and the minimum torque $(T)$ for the tapping process. This study reports a BoxBehnken design (BBD) using DEFORM-3D (finite element model) and MINITAB (regression analysis) software to tap 7075-T6 aluminum alloy using a small FFT to achieve a repeatable thread filling rate and minimum torque. The experimental results show that the BBD accurately predicts and simulate the thread filling rate for tapping 7075-T6 aluminum alloy. The modelling software and the
\end{abstract}


experimental design for this study can be used to optimize the design of tools that are used in industrial production.

Keywords: Fluteless forming tap, Tapping, 7075-T6 aluminum alloy, Thread filling rate, Torque

\section{Introduction}

As 3C electronic products (mobile phones, iPads, laptops and smart watches) become thinner and lighter, the manufacturing process for SBITs requires greater accuracy in terms of geometry and size to achieve better fastening. Traditional taps produce chips during the tapping process, which are difficult to remove from a hole with a small diameter in a workpiece. SBIT tapping is often the last process in machining the cover of $3 \mathrm{C}$ electronic products. If the SBIT profile cannot be tapped completely, the fastening fails. Therefore, it is difficult to manufacture high-quality SBITs for the covers of $3 \mathrm{C}$ electronic products. A fluteless forming tap (FFT), which does not produce chips during the tapping process, produces a blind internal thread profile through plastic deformation.

Previous studies show the effect of hole-diameter, forming speed, tool hardness, thread filling rate and tool geometry on the tapping torque and force [1-6]. Warrington [7] and Mathurin [8] used a finite element model to simulate the effect of a fluteless forming tapping process, various tool design parameters and tapping conditions on the split crest. The simulation results were verified through experiments. Stéphan [9] used slip line theory to determine the maximum torque for a FFT during the tapping process. Huang [10] established a mathematical model to calculate the tapping force and the torque for a tool and to determine the design of parameters for tool geometry. Carvalho [11] and Filho [12] sectioned experimental workpieces to determine the surface quality of the internal thread profile using a microscope. Tsao and Kuo [13] used image processing software to determine thread filling rate for a tapped SBIT.

Currently, M1.2 $\times 0.25 \mathrm{~mm}$ taps are widely used to generate SBITs for the covers of mobile phones. The contour of a SBIT is not easily observed or measured with the naked eye but a computer can be used to quickly establish and measure the area and tooth profile for a SBIT. Finite element 
analysis (FEA) is used to determine the plastic flow in metal materials. Mathurin [8] also showed that finite element software (DEFORM-3D) can be used to solve the complex plastic forming problems for blind internal threads to calculate the stress, strain, displacement and velocity. The best tool design parameters were determined using a design of experiment (DoE). An optimal tool geometry increases the thread filling rate and decreases the minimum torque during tapping.

This study uses the statistical software (MINITAB) and a BBD to establish a regression model for the thread filling rate and the minimum torque. This regression model is used to determine the best geometric parameters for a FFT to achieve the best thread filling rate and the minimum torque. These regression models are used to design the geometry of the tapping tool, to improve the quality of the thread and to reduce research and design costs.

\section{Methodology}

In order to cause plastic deformation in a ductile material and ensure that no chips are generated during the tapping process, the geometric characteristics of a FFT must be different to those of a traditional tap. In terms of appearance, a FFT does not require a flute design for chip removal or chip breaking. The quality characteristic of an internal thread that is produced using a FFT depends on the outer diameter $\left(D_{1}\right)$, the tooth root diameter $\left(D_{2}\right)$, the tool pitch $(P)$, the tool width $(W)$, the front-end diameter $\left(D_{f}\right)$ and the tooth angle $(\theta)$, as shown in Fig. 1. The FFT for this study is made of tungsten carbide. A M1.2 $\times 0.25 \mathrm{~mm}$ tap must comply with the ISO $68-1$ thread profile and internal threads must comply with a gauge test (CNS533 B6013).

This study involves an internal thread with an outer diameter for the FFT of $1.245 \mathrm{~mm}$, a tooth root diameter of $0.95 \mathrm{~mm}$, an inner diameter $\left(D_{3}\right)$ of $0.84 \mathrm{~mm}$ and a front-end diameter of $1.0 \mathrm{~mm}$. The inner diameter $\left(D_{3}\right)$ is defined as $D_{3}=D_{2}-0.11$. Other tool parameters are also shown in Table 1. According to the study by Stéphan [9], increasing the number of lobes prevents deviation of the central axis of the tool during the tapping process, but torque also increases as the contact area increases. Therefore, four lobes are used to maintain stable tool rotation and to prevent an excessive torque load. To reduce the cost and weight, the cover for a mobile phone is about 1.5 2.0 mm thick. 
The tool cannot run too deep or run through the cover of mobile phone, so the chamfer length for the FFT for this study is about $0.25 \mathrm{~mm}$ (1 pitch).

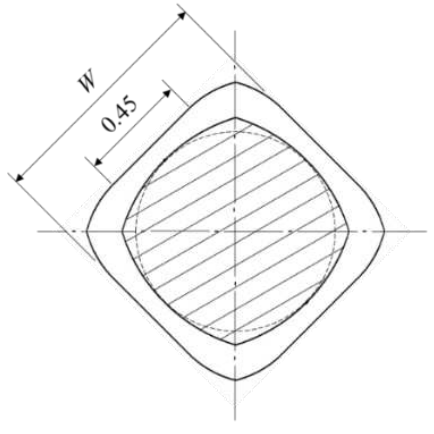

(a) Cross Section A-A

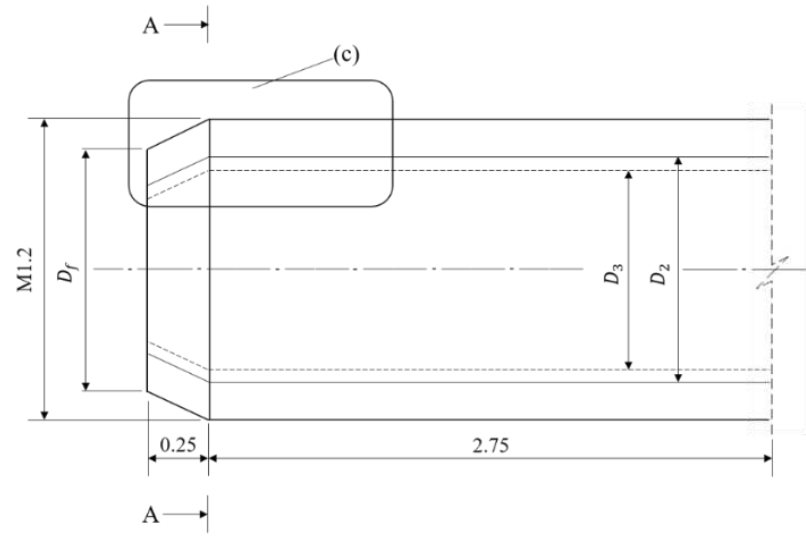

(b) M1.2 tap

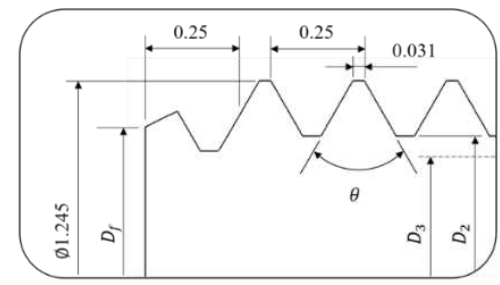

(c) Thread profile

Fig. 1 Geometric characteristics of the FFT $(\mathrm{M} 1.2 \times 0.25 \mathrm{~mm})$

Table 1 Tool parameters

\begin{tabular}{ll}
\hline Terms & Value \\
\hline Outer diameter, $D_{1}(\mathrm{~mm})$ & 1.245 \\
Tooth root diameter, $D_{2}(\mathrm{~mm})$ & 0.95 \\
Inner diameter, $D_{3}(\mathrm{~mm})$ & 0.84 \\
Front-end diameter, $D_{f}(\mathrm{~mm})$ & 1.0 \\
Chamfer length $(\mathrm{mm})$ & 0.25 \\
Tool pitch, $P(\mathrm{~mm})$ & 0.25 \\
Tooth width $(\mathrm{mm})$ & 0.031 \\
Tooth height $(\mathrm{mm})$ & 0.1475 \\
Tool width, $W(\mathrm{~mm})$ & 1.0
\end{tabular}




$\begin{array}{lc}\text { Lobe length }(\mathrm{mm}) & 0.45 \\ \text { Tooth angle, } \theta\left(^{\circ}\right) & 60 \\ \text { Tool length }(\mathrm{mm}) & 3.0\end{array}$

\subsection{Experiments}

This study uses a workpiece (7075-T6 aluminum alloy) that is $5.0 \mathrm{~mm}$ thick. All tapping experiments were conducted three times using a Brother S500X1 machining center. The process parameters for the tapping experiment are shown in Table 2. A schematic diagram of the experimental setup is shown in Fig. 2, which shows that the tapping tool is clamped in the CNC tool holder and controlled using G-code. In Table 2, the rotation speed is $4,000 \mathrm{rpm}$ and the tool pitch is $0.25 \mathrm{~mm}$, so the feed rate $(F)$ is $1,000 \mathrm{~mm} / \mathrm{min}$.

The tool is positioned above the hole and fed downward from point (a) and rotates clockwise into the hole. The tool stops when the tapping depth reaches $1.5 \mathrm{~mm}$ at point (b). Point (c) marks the retracted stroke when thread processing is complete. The machining center then moves the tool to the next hole, which is marked as point (d). The torque during tapping was measured using a Kistler 9273 piezoelectric dynamometer and Kistler 5011 charge amplifiers using a NI-6110S data acquisition (DAQ) card and recorded using a personal computer (PC). The diameter and depth of the pre-drilled hole are $1.07 \mathrm{~mm}$ and $2.0 \mathrm{~mm}$, respectively. The feed rate $(F)$ is defined in terms of the tool rotation speed $(\omega)$ and the tool pitch $(P)$ as:

$$
F=\omega \times P
$$




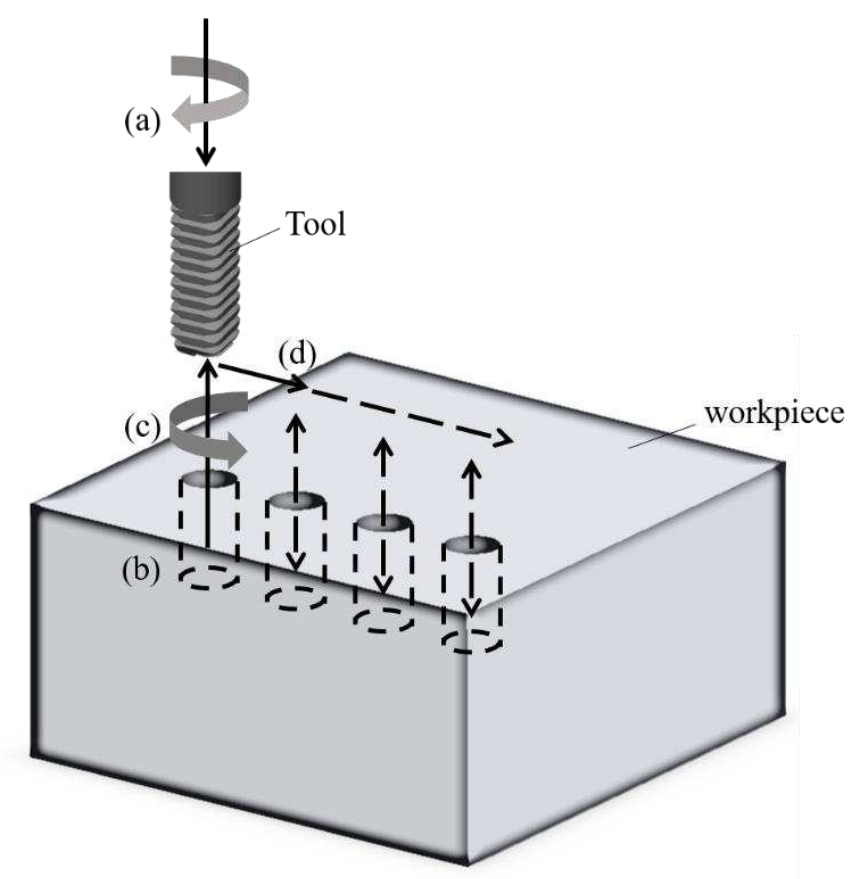

Fig. 2 Schematic diagram of the experimental setup

Table 2 Tapping process parameters

\begin{tabular}{ll}
\hline Terms & Value \\
\hline Workpiece material & 7075-T6 aluminum alloy \\
Lubricating oil & Castrol Alusol SL51 XBB \\
Plate thickness (mm) & 5.0 \\
Pre-drill diameter (mm) & 1.07 \\
Pre-drill hole depth (mm) & 2.0 \\
Pre-drill pitch (mm) & 4.0 \\
Feed rate (mm/min) & 1,000 \\
Rotation speed (rpm) & 4,000 \\
Processing stroke (mm) & 1.5 \\
\hline
\end{tabular}

The tapped workpiece was then cut in half using a wire-EDM machine. Ignoring the workpiece material that is consumed by the wire-cut diameter, the cut hole in the workpiece is regarded as a complete semicircle. Fig. 3 shows a schematic diagram of the cutting workpiece. After scanning, the 
cross-section of the hole is shown in Fig. 4, which shows an image of the SBIT profile using a metallographic microscope. The serrated areas on both sides of Fig. 4 are the SBIT profile. The 8 numbered teeth on the top are used for measurements because the first-four threads are the most important for fastening the component and the cover of mobile phone using a screw.

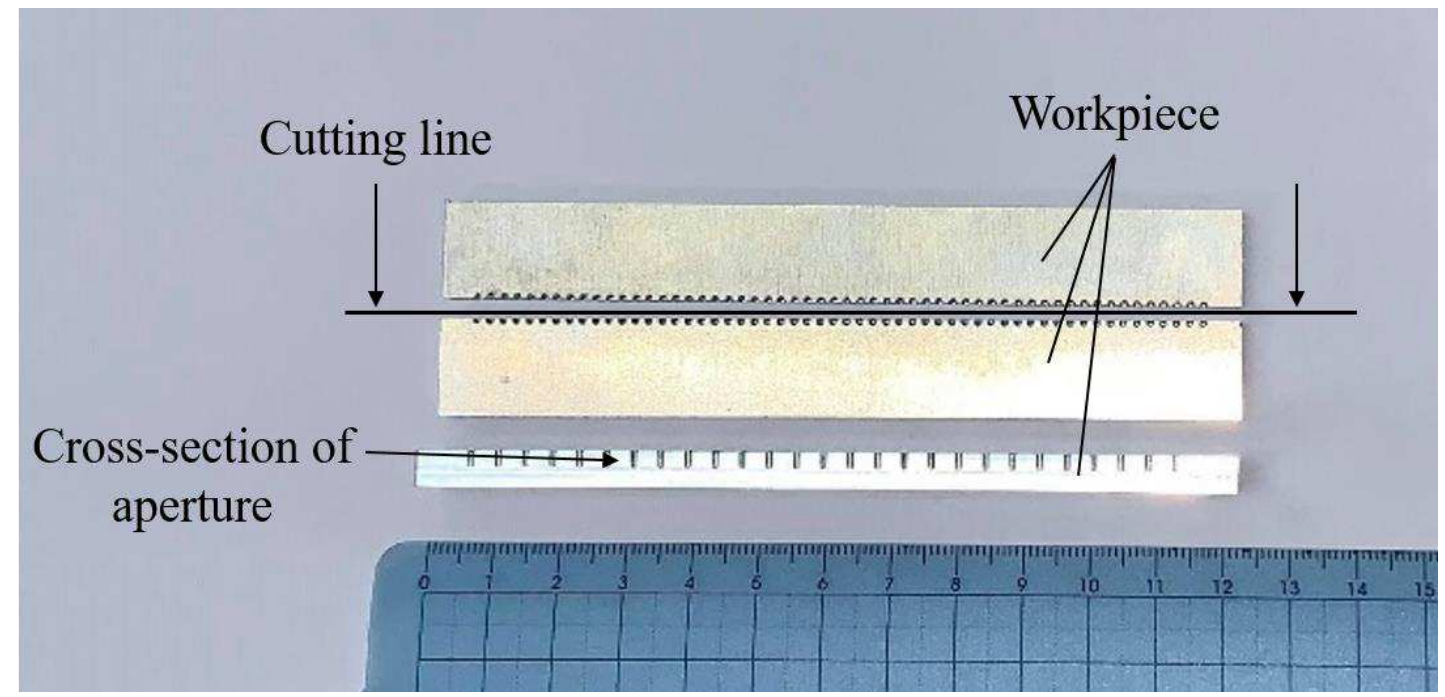

Fig. 3 Schematic diagram of the cutting workpiece

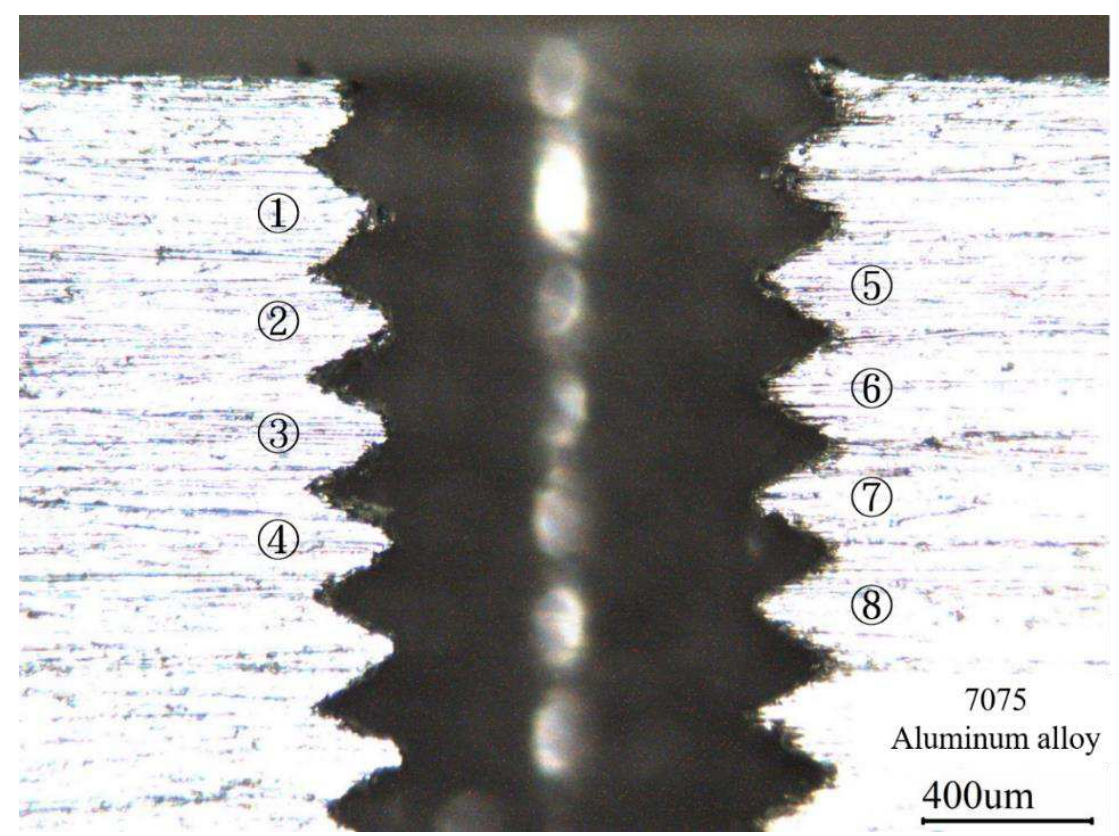

Fig. 4 Scanned SBIT profile

\subsection{Binarization}

Image processing software (ImageJ) was used to determine the SBIT profile after tapping the 
workpiece, which is related to the thread filling rate $(f)$. The binarization method for the SBIT profile uses a grayscale threshold to calculate the image area in terms of pixels. The grayscale threshold is manually adjusted or automatically calculated (auto threshold). For this study, the Renyi Entropy algorithm is used to calculate all image areas for the tapped thread [14]. Particle analysis is used to calculate the thread area and the result is given in units of $\mathrm{mm}^{2}$. The thread filling rate $(f)$ is defined as:

$$
f=A_{E} / A_{I} \times 100 \%
$$

where $A_{E}$ is the experimental thread area and $A_{I}$ is the ideal thread area. Fig. 5 shows a schematic diagram of an ideal thread shape, for which the area is calculated as $0.01974 \mathrm{~mm}^{2}$. The experimental tooth area is measured using the image processing software and the ideal tooth area gives the maximum projection range between the workpiece and the tool.

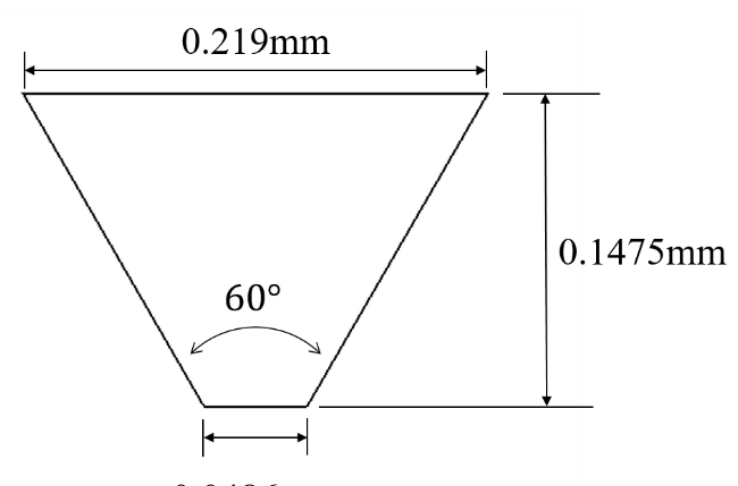

$0.0486 \mathrm{~mm}$

Fig. 5 Schematic diagram of an ideal tooth shape

\subsection{Box-Behnken design}

A Box-Behnken design is an experimental design for response surface methodology (RSM) and is more convenient and accurate than other designs. RSM is used to solve an optimization problem with exact limitations. This study uses RSM to determine the relationship between four explanatory variables $\left(W, D_{2}, D_{f}\right.$ and $\left.\theta\right)$ and two response variables $(f$ and $T)$. The selected factors and levels for this study are shown in Table 3. The factorial experiments were repeated 3 times and one center point are used for the experiment, as shown in Table 4. The result of the factorial experiment using a BBD is used to establish the second-order model to optimize the response variables. 
Table 3 Factors and levels

\begin{tabular}{c|cccc}
\hline & $W(\mathbf{M M})$ & $\boldsymbol{D}_{\mathbf{2}}(\mathrm{mm})$ & $\boldsymbol{D}_{f}(\mathrm{~mm})$ & $\boldsymbol{\theta}\left({ }^{\circ}\right)$ \\
\hline $\mathbf{1}$ & 1.065 & 0.9714 & 1.0394 & 62.17 \\
$\mathbf{0}$ & 1.015 & 0.9514 & 0.9994 & 60.17 \\
$\mathbf{- 1}$ & 0.965 & 0.9314 & 0.9594 & 58.17 \\
\hline
\end{tabular}

Table 4 Table for the Box-Behnken design

\begin{tabular}{|c|c|c|c|c|}
\hline NO. & $\boldsymbol{W}$ & $D_{2}$ & $D_{f}$ & $\boldsymbol{\theta}$ \\
\hline 1 & -1 & -1 & 0 & 0 \\
\hline 2 & -1 & 1 & 0 & 0 \\
\hline 3 & 1 & -1 & 0 & 0 \\
\hline 4 & 1 & 1 & 0 & 0 \\
\hline 5 & -1 & 0 & -1 & 0 \\
\hline 6 & -1 & 0 & 1 & 0 \\
\hline 7 & 1 & 0 & -1 & 0 \\
\hline 8 & 1 & 0 & 1 & 0 \\
\hline 9 & -1 & 0 & 0 & -1 \\
\hline 10 & -1 & 0 & 0 & 1 \\
\hline 11 & 1 & 0 & 0 & -1 \\
\hline 12 & 1 & 0 & 0 & 1 \\
\hline 13 & 0 & -1 & -1 & 0 \\
\hline 14 & 0 & -1 & 1 & 0 \\
\hline 15 & 0 & 1 & -1 & 0 \\
\hline 16 & 0 & 1 & 1 & 0 \\
\hline 17 & 0 & -1 & 0 & -1 \\
\hline 18 & 0 & -1 & 0 & 1 \\
\hline 19 & 0 & 1 & 0 & -1 \\
\hline 20 & 0 & 1 & 0 & 1 \\
\hline 21 & 0 & 0 & -1 & -1 \\
\hline 22 & 0 & 0 & -1 & 1 \\
\hline 23 & 0 & 0 & 1 & -1 \\
\hline 24 & 0 & 0 & 1 & 1 \\
\hline
\end{tabular}




\section{Finite element method (FEM)}

\subsection{Modelling}

This study models the solutions of finite element analysis (FEA) based on the following assumptions: (1) the model is homogeneous, isotropic and complies with von-Mises yield criterion; (2) the model has plastic incompressibility; (3) the tool is regarded as a completely rigid body; (4) the thermal effect of the model is ignored and (5) the rotation process quasi-static and the analysis is performed in incremental steps.

To study the SBIT for a single hole, the model of the workpiece is simplified as a cylinder with an outer diameter of $2.5 \mathrm{~mm}$, an inner diameter of $1.07 \mathrm{~mm}$ and a workpiece thickness of $2 \mathrm{~mm}$. The material model uses 7075-T6 aluminum alloy from the Deform-3D database. The simulation ignores the effects of elastic recovery and temperature. Room temperature is fixed at $20^{\circ} \mathrm{C}$ for the form tapping analysis model. The tool and workpiece are modeled using SolidWorks software and imported into Deform-3D as a STL-file. The tool specification is $\mathrm{M} 1.2 \times 0.25 \mathrm{~mm}$ and the geometric parameters are shown in Section 2.1. The initial position of tool and workpiece model for the simulation is shown in Fig. 6. The plane of the front-end of the tool and the top of workpiece are at the same level so the descending stroke and the processing depth of workpiece are synchronized. This clarifies the relationship between tool stroke and blind internal thread formation. The interface friction between the tool and the workpiece is shear friction. The shear friction factor $(\mathrm{m})$ is 0.1 . The feed rate for the tool is $1,000 \mathrm{~mm} / \mathrm{min}(16.67 \mathrm{~mm} / \mathrm{s})$, the rotation speed is $4,000 \mathrm{rpm}$ and the processing stroke is 1.5 $\mathrm{mm}$. 


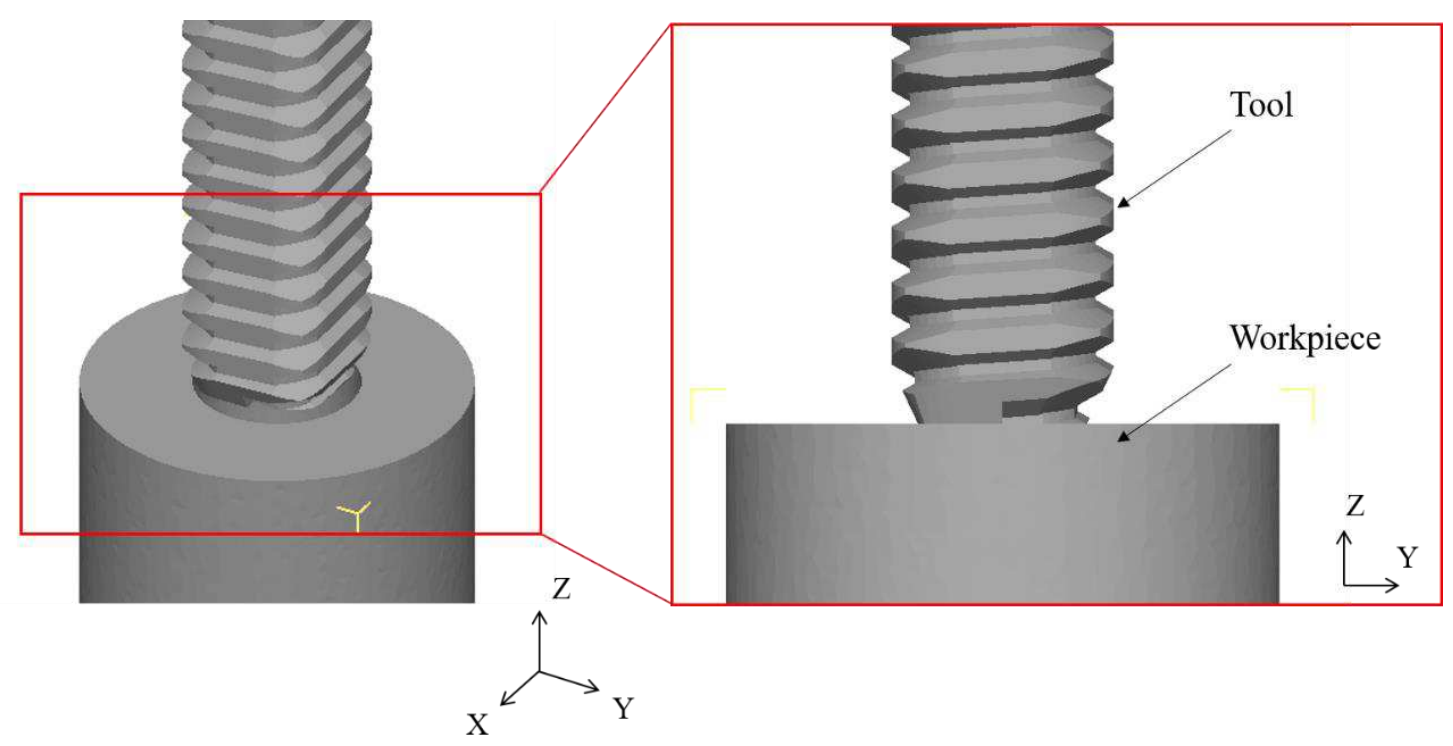

Fig. 6 The initial position of the tool and workpiece model for the simulation

Formentin [4] showed that the main deformation region for a FFT is concentrated in the thread surface of the inner hole and other materials are not deformed. The geometry of the blind internal thread profile is more complicated so the local mesh for the thread deformed area corresponding to the workpiece model must be refined. Fig. 7 shows a schematic diagram of the local mesh refinement for the workpiece model. The minimum edge length for the mesh is $0.02 \mathrm{~mm}$. For this study, the number of finite element meshes is determined using convergence analysis. Using the convergence results for thread filling rate and minimum torque, the number of mesh groups is 8 . Figs. 8 and 9 respectively show the relationship between the thread filling rate and the minimum torque and the number of meshes. The thread filling rate and the minimum torque converge to a stable value when the number of meshes exceeds 80,000 . Therefore, this study uses 85,000 meshes to establish a finite element model of the workpiece. 


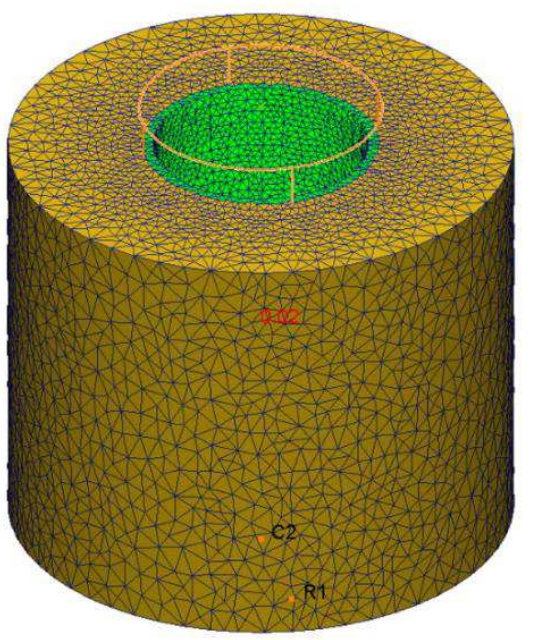

(a) Entity

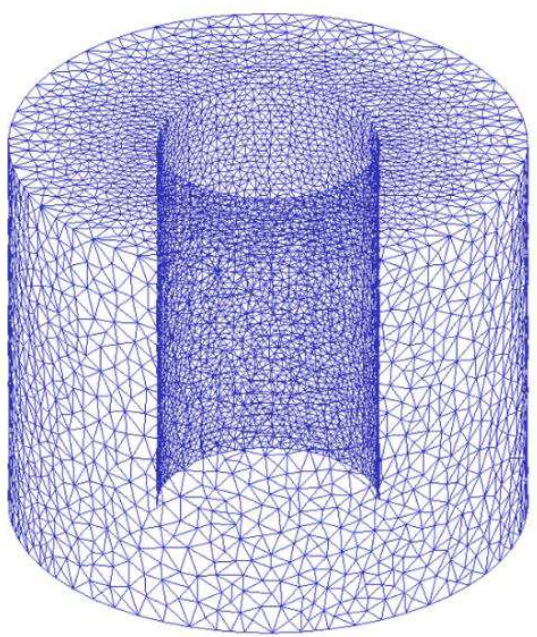

(b) Mesh

Fig. 7 Local mesh refinement for the workpiece model

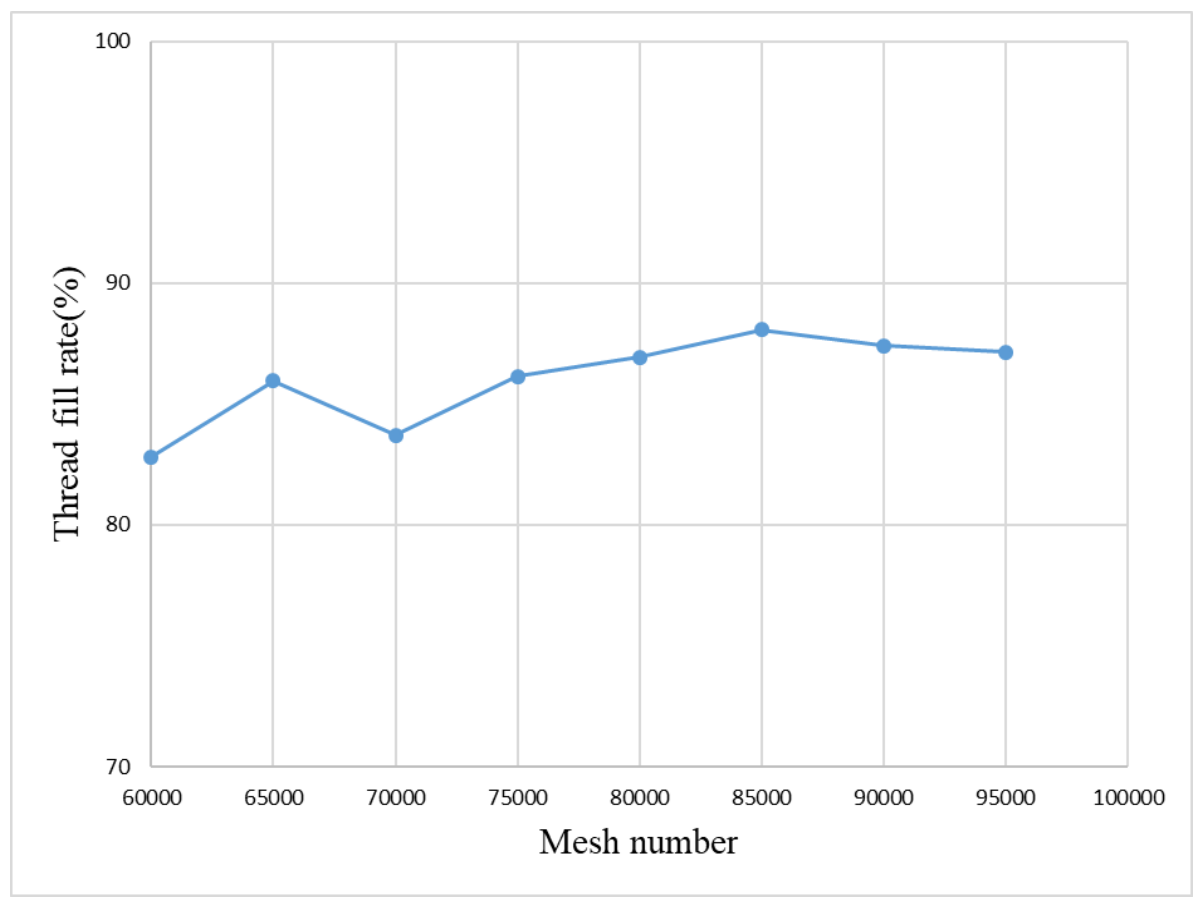

Fig. 8 Convergence analysis for the thread filling rate and the mesh number 


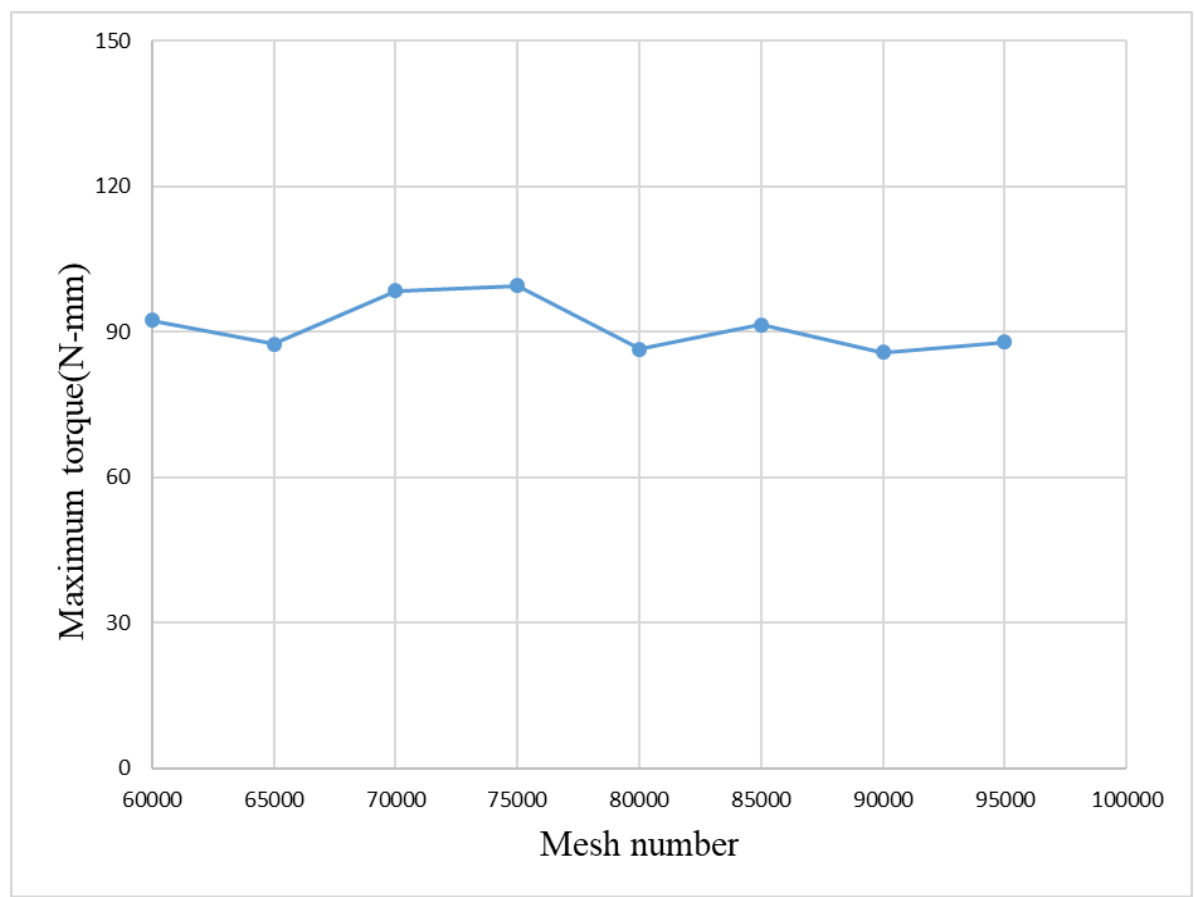

Fig. 9 Convergence analysis for the minimum torque and the mesh number

\subsection{Thread filling rate}

The simulation and the experimental results are compared to verify whether the blind internal thread profile is correct. Fig. 10 shows an overlay of the simulation and experimental results (solid line) for the blind internal thread profile. Nos. $1 \sim 8$ in Fig. 10 are the same as the simulation measurements in Fig. 4. ImageJ software was used to scan the image in the microscope to measure the area of each thread in the $\mathrm{X}-\mathrm{Z}$ and $\mathrm{Y}-\mathrm{Z}$ planes and these 8 sets of measurement data are used to determine the thread filling rate for each thread. For this study, the average simulated thread filling rates are $87.59 \%$ and $88.57 \%$ in the $\mathrm{X}-\mathrm{Z}$ and $\mathrm{Y}-\mathrm{Z}$ planes. The average experimental thread filling rates are $89.41 \%$ and $91.28 \%$ in $\mathrm{X}-\mathrm{Z}$ and $\mathrm{Y}-\mathrm{Z}$ planes. There is little difference between the average thread filling rate for the simulation and the experiment in the $\mathrm{X}-\mathrm{Z}$ and $\mathrm{Y}-\mathrm{Z}$ planes, as shown in Table 5. The circles in Fig. 10 indicate burrs that are generated during the forming process. The direction of the burr in Figs. 10(a) and 10(b) is different, because the initial contact points for processing are different. The arrows in Fig. 10 show the different phase angles and different initial contact points that result in a mismatched thread profile. 


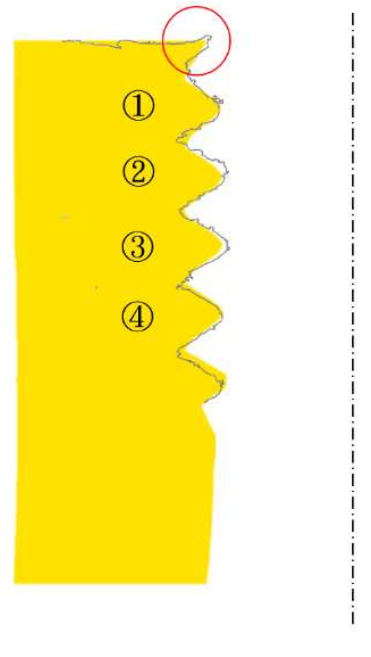

(a) $\mathrm{X}-\mathrm{Z}$ plane

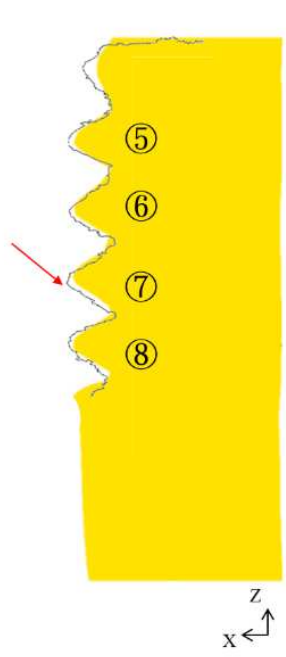

$\uparrow$

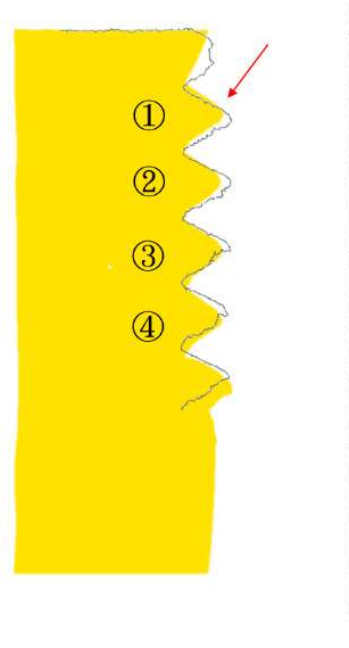

(b) Y-Z plane

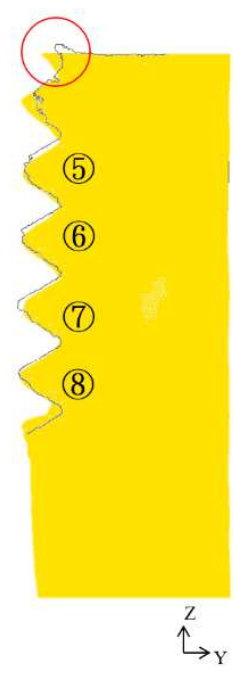

Fig. 10 Validation of the internal thread profile for different planes

Table 5 Thread filling rate $(\%)$ for different planes

\begin{tabular}{cccc|ccc}
\hline \multicolumn{4}{c}{ X-Z plane } \\
\hline No. & Simulation Experiment & Error (\%) & Simulation & Experiment & Error (\%) \\
\hline 1 & 84.40 & 76.42 & 10.44 & 84.22 & 89.42 & 5.82 \\
2 & 86.12 & 90.73 & 5.08 & 85.67 & 90.47 & 5.31 \\
3 & 85.07 & 94.23 & 9.72 & 93.11 & 92.11 & 1.09 \\
4 & 92.05 & 93.79 & 1.86 & 86.17 & 88.53 & 2.67 \\
5 & 87.33 & 88.61 & 1.44 & 88.56 & 86.97 & 1.83 \\
6 & 90.22 & 89.43 & 0.88 & 91.13 & 94.68 & 3.75 \\
7 & 84.22 & 91.16 & 7.61 & 92.98 & 95.83 & 2.97 \\
8 & 91.28 & 90.94 & 0.37 & 86.72 & 92.25 & 5.99 \\
\hline Avg. & 87.59 & 89.41 & 4.68 & 88.57 & 91.28 & 3.68 \\
\hline
\end{tabular}

\subsection{Minimum torque}

For a small forming tap, excessive torque causes damage or breakage of a tool during the tapping process. Fig. 11 shows the relationship between time and torque for a tapping process using a small 
forming tap. Zone (a) is the initial point of contact between the tool and the workpiece. The torque increases rapidly from zero on a steep gradient. In Zone (b), the tool continues to enter the hole. The torque increases as the stroke increases and there is a minimum torque of $87.21 \mathrm{~N}-\mathrm{mm}$ after 0.08755 sec. In Zone (c), the tool reaches the bottom of the hole (tool stroke of $1.5 \mathrm{~mm}$ ) after a processing time of about $0.09 \mathrm{sec}$. At this time, the tap stops rotating and feeding so the torque is $0 \mathrm{~N}-\mathrm{mm}$. Zone (d) is the retract stroke stage, when the contact area between the tool and the workpiece gradually decreases so the torque gradually decreases as time increases until the tool is separated from the workpiece. The torque is then $0 \mathrm{~N}-\mathrm{mm}$ and the entire tapping process is completed. In order to simplify the simulation process, this study only considers the minimum torque that is generated in zones (a)-(b).

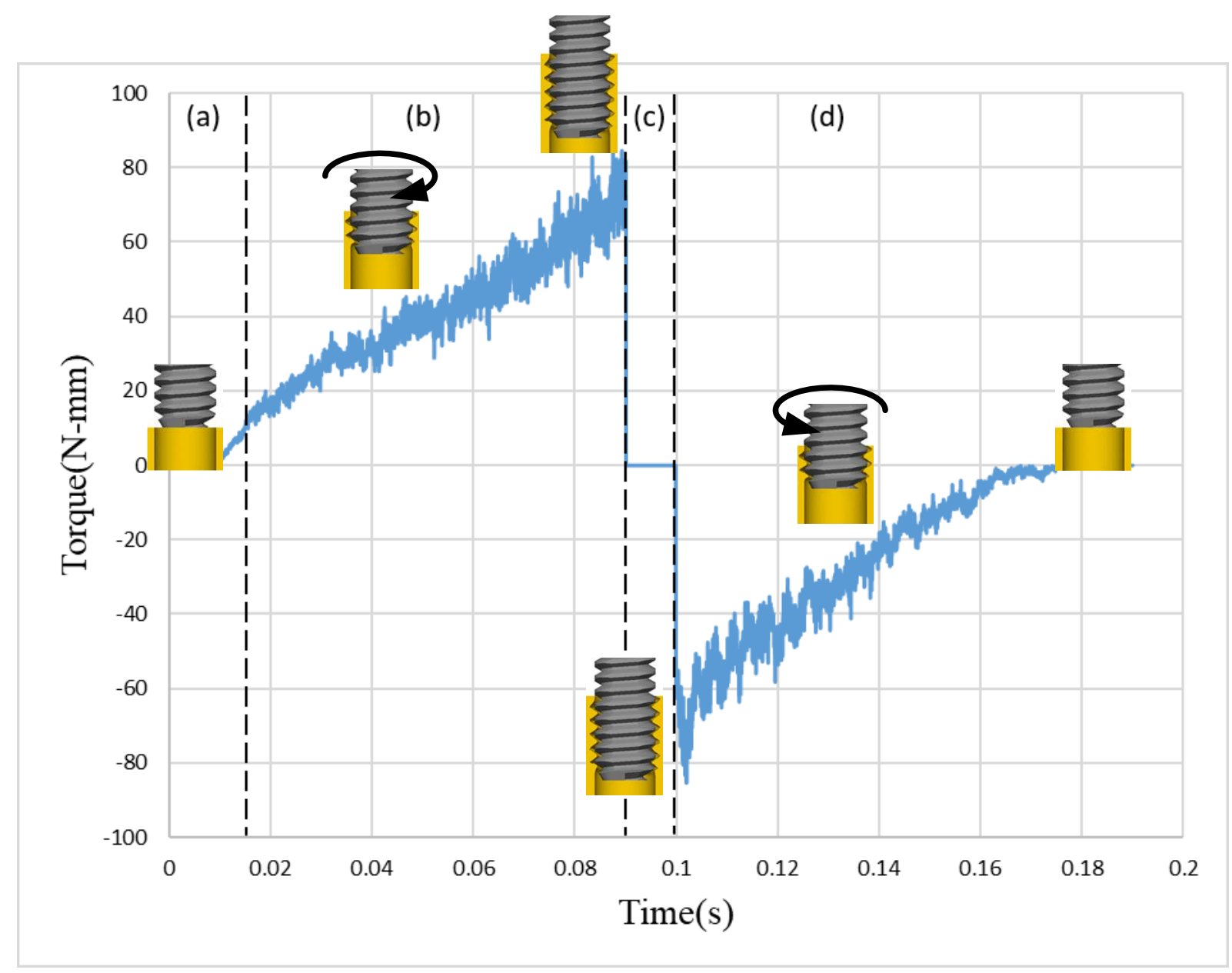

Fig. 11 Torque distribution for the forming internal thread

\section{Results and discussion}




\subsection{Factorial analysis}

The simulation results using DEFORM-3D software are shown in Table 6. To determine the relationship between various parameters and quality characteristics for FFTs that are used to tap 7075T6 aluminum alloy, a second-order regression model is established using MINITAB software to predict equations for the thread filling rate $\left(f_{1}\right)$ and minimum torque $\left(T_{1}\right)$. These two second-order regression models are expressed as:

$f_{1}=88.85+11.53 W+1.9708 D_{2}-1.8075 D_{f}+2.0717 \theta-5.3221 W^{2}-3.6358 D_{2}^{2}-$

$2.4058 D_{f}^{2}-0.4221 \theta^{2}-1.295 W D_{2}+0.3425 W D_{f}+0.2825 W \theta+0.555 D_{2} D_{f}-1.3175 D_{2} \theta-$ $0.005 D_{f} \theta$

$T_{1}=89.08-6.235 W+6.8958 D_{2}+1.0058 D_{f}+5.5867 \theta+5.0517 W^{2}+1.0829 D_{2}^{2}-$

$1.9221 D_{f}^{2}+6.0292 \theta^{2}-0.7975 W D_{2}+1.5575 W D_{f}+0.675 W \theta-1.17 D_{2} D_{f}-0.245 D_{2} \theta-$ $2.545 D_{f} \theta$

Table 6 Simulation results for Box-Behnken design

\begin{tabular}{|c|c|c|c|c|c|c|}
\hline NO. & $\boldsymbol{W}$ & $D_{2}$ & $D_{F}$ & $\theta$ & $f(\%)$ & $T(\mathbf{N}-\mathbf{m m})$ \\
\hline 1 & -1 & -1 & 0 & 0 & 68.26 & 92.16 \\
\hline 2 & -1 & 1 & 0 & 0 & 72.42 & 108.95 \\
\hline 3 & 1 & -1 & 0 & 0 & 91.80 & 81.54 \\
\hline 4 & 1 & 1 & 0 & 0 & 90.78 & 95.14 \\
\hline 5 & -1 & 0 & -1 & 0 & 69.20 & 99.77 \\
\hline 6 & -1 & 0 & 1 & 0 & 65.29 & 93.49 \\
\hline 7 & 1 & 0 & -1 & 0 & 93.84 & 83.58 \\
\hline 8 & 1 & 0 & 1 & 0 & 91.30 & 83.53 \\
\hline 9 & -1 & 0 & 0 & -1 & 71.06 & 105.80 \\
\hline 10 & -1 & 0 & 0 & 1 & 72.83 & 112.41 \\
\hline 11 & 1 & 0 & 0 & -1 & 93.40 & 92.33 \\
\hline 12 & 1 & 0 & 0 & 1 & 96.30 & 101.64 \\
\hline 13 & 0 & -1 & -1 & 0 & 82.08 & 81.87 \\
\hline 14 & 0 & -1 & 1 & 0 & 77.73 & 85.99 \\
\hline 15 & 0 & 1 & -1 & 0 & 87.36 & 98.60 \\
\hline 16 & 0 & 1 & 1 & 0 & 85.23 & 98.04 \\
\hline
\end{tabular}




\begin{tabular}{c|cccccc}
$\mathbf{1 7}$ & 0 & -1 & 0 & -1 & 76.59 & 80.99 \\
$\mathbf{1 8}$ & 0 & -1 & 0 & 1 & 86.70 & 95.37 \\
$\mathbf{1 9}$ & 0 & 1 & 0 & -1 & 83.09 & 93.27 \\
$\mathbf{2 0}$ & 0 & 1 & 0 & 1 & 87.93 & 106.67 \\
$\mathbf{2 1}$ & 0 & 0 & -1 & -1 & 87.82 & 80.33 \\
$\mathbf{2 2}$ & 0 & 0 & -1 & 1 & 90.45 & 97.09 \\
$\mathbf{2 3}$ & 0 & 0 & 1 & -1 & 83.45 & 92.84 \\
$\mathbf{2 4}$ & 0 & 0 & 1 & 1 & 86.06 & 99.42 \\
Centre & 0 & 0 & 0 & 0 & 88.85 & 89.08 \\
\hline
\end{tabular}

Table 7 show the results for the analysis of variance (ANOVA) for the thread filling rate $\left(f_{1}\right)$ and minimum torque $\left(T_{1}\right)$. The results of the ANOVA show that the determination coefficients $\left(R^{2}\right)$ for $f_{1}$ and $T_{1}$ are $97.0 \%$ and $90.6 \%$, so the two second-order models are significant. For a factor confidence level of $95 \%$, the $\mathrm{T}$-value is less than $\mathrm{T}_{(0.05 / 2,10)}=2.228$, which signifies an insignificant factor item. In Table 7, $W, D_{2}, D_{f}$ and $\theta$ are the parameters that affect $f_{1}$, and $W, D_{2}$ and $\theta$ affect $T_{1}$. As $W$ decreases, the thread filling rate increases and the tapping torque decreases. The smaller the value of $D_{2}$, the greater is the thread filling rate and the smaller is the minimum torque.

In terms of the strength of the FFT during tapping, the value of $D_{2}$ of the FFT must not be too small. The value of $\theta$ must also be sufficiently large. $D_{f}$ does not have a significant effect on the minimum torque because the chamfer on the FFT for this study is only $0.25 \mathrm{~mm}$ ( 1 pitch). Table 7 also shows that the first-order interaction factor does not have a significant effect on the thread filling rate and the minimum torque. Table 8 shows the results for simulation and the prediction data for $f_{1}$ and $T_{1}$. The errors (\%) in $f_{1}$ and $T_{1}$ are less than $6 \%$, so the two second-order models are appropriate.

Table 7 Analysis of variance for the thread filling rate $\left(f_{1}\right)$ and the minimum torque $\left(T_{1}\right)$

\begin{tabular}{ccc}
\hline ANOVA & \multicolumn{2}{c}{ P VALUE $(\mathbf{P}<\mathbf{0 . 0 5})$} \\
\hline & $f_{1}$ & $T_{1}$ \\
\cline { 2 - 3 } $\boldsymbol{R}^{2}$ & $97.0 \%$ & $90.6 \%$ \\
F-TEST & 23.16 & 6.91 \\
\cline { 2 - 3 }
\end{tabular}




\begin{tabular}{lcccc} 
& T-value & P value & T-value & P value \\
\hline INTER & & & & \\
CEPT & 36.86 & $5.14 \mathrm{E}-12$ & 20.54 & $1.65 \mathrm{E}-09$ \\
$\boldsymbol{W}$ & 16.57 & $1.34 \mathrm{E}-08$ & -4.98 & $5.53 \mathrm{E}-04$ \\
$\boldsymbol{D}_{\mathbf{2}}$ & 2.83 & 0.018 & 5.51 & $2.59 \mathrm{E}-04$ \\
$\boldsymbol{D}_{\boldsymbol{f}}$ & -2.60 & 0.027 & 0.80 & 0.440 \\
$\boldsymbol{\theta}$ & 2.98 & 0.014 & 4.46 & 0.001 \\
$\boldsymbol{W}^{\mathbf{2}}$ & -3.71 & 0.004 & 1.96 & 0.079 \\
$\boldsymbol{D}_{\mathbf{2}}^{\mathbf{2}}$ & -2.53 & 0.030 & 0.42 & 0.684 \\
$\boldsymbol{D}_{\boldsymbol{f}}^{\mathbf{2}}$ & -1.68 & 0.124 & -0.74 & 0.474 \\
$\boldsymbol{\theta}^{\mathbf{2}}$ & -0.29 & 0.775 & 2.34 & 0.042 \\
$W \times \boldsymbol{D}_{\mathbf{2}}$ & -1.07 & 0.308 & -0.37 & 0.721 \\
$W \times \boldsymbol{D}_{\boldsymbol{f}}$ & 0.28 & 0.782 & 0.72 & 0.489 \\
$W \times \Theta$ & 0.23 & 0.819 & 0.31 & 0.762 \\
$\boldsymbol{D}_{\mathbf{2}} \times \boldsymbol{D}_{\boldsymbol{f}}$ & 0.46 & 0.665 & -0.54 & 0.601 \\
$\boldsymbol{D}_{\mathbf{2}} \times \boldsymbol{\theta}$ & -1.09 & 0.300 & -0.11 & 0.912 \\
$\boldsymbol{D}_{\boldsymbol{f}} \times \boldsymbol{\theta}$ & 0.00 & 0.997 & -1.17 & 0.268 \\
\hline & & & & \\
\hline & & & & \\
\hline
\end{tabular}

Table 8 Results for the simulation and the prediction data for $f_{1}$ and $T_{1}$

\begin{tabular}{cccc|ccc}
\hline \multicolumn{4}{c}{$f_{1}$} \\
\hline No. & Simulation & Prediction & Error $(\%)$ & Simulation & Prediction & Error (\%) \\
\hline 1 & 68.26 & 65.10 & 4.63 & 92.16 & 93.76 & 1.73 \\
2 & 72.42 & 71.63 & 1.09 & 108.95 & 109.14 & 0.18 \\
3 & 91.80 & 90.75 & 1.15 & 81.54 & 82.88 & 1.64 \\
4 & 90.78 & 92.10 & 1.45 & 95.14 & 95.08 & 0.07 \\
5 & 69.20 & 71.74 & 3.67 & 99.77 & 99.00 & 0.78
\end{tabular}




\begin{tabular}{|c|c|c|c|c|c|c|}
\hline 6 & 65.29 & 67.44 & 3.30 & 93.49 & 97.89 & 4.71 \\
\hline 7 & 93.84 & 94.12 & 0.30 & 83.58 & 83.41 & 0.20 \\
\hline 8 & 91.30 & 91.19 & 0.12 & 83.53 & 88.54 & 6.00 \\
\hline 9 & 71.06 & 69.79 & 1.79 & 105.80 & 101.48 & 4.08 \\
\hline 10 & 72.83 & 73.37 & 0.73 & 112.41 & 111.31 & 0.98 \\
\hline 11 & 93.40 & 92.28 & 1.20 & 92.33 & 87.66 & 5.05 \\
\hline 12 & 96.30 & 96.99 & 0.72 & 101.64 & 100.19 & 1.43 \\
\hline 13 & 82.08 & 83.20 & 1.36 & 81.87 & 79.17 & 3.30 \\
\hline 14 & 77.73 & 78.48 & 0.96 & 85.99 & 83.52 & 2.87 \\
\hline 15 & 87.36 & 86.03 & 1.52 & 98.60 & 95.30 & 3.35 \\
\hline 16 & 85.23 & 83.53 & 2.00 & 98.04 & 94.97 & 3.13 \\
\hline 17 & 76.59 & 79.43 & 3.71 & 80.99 & 83.47 & 3.06 \\
\hline 18 & 86.70 & 86.21 & 0.56 & 95.37 & 95.13 & 0.25 \\
\hline 19 & 83.09 & 86.01 & 3.51 & 93.27 & 97.75 & 4.80 \\
\hline 20 & 87.93 & 87.52 & 0.47 & 106.67 & 108.43 & 1.65 \\
\hline 21 & 87.82 & 85.75 & 2.35 & 80.33 & 84.05 & 4.63 \\
\hline 22 & 90.45 & 89.91 & 0.60 & 97.09 & 100.31 & 3.32 \\
\hline 23 & 83.45 & 82.15 & 1.56 & 92.84 & 91.15 & 1.82 \\
\hline 24 & 86.06 & 86.28 & 0.26 & 99.42 & 97.24 & 2.20 \\
\hline Centre & 88.85 & 88.85 & 0.00 & 89.08 & 89.08 & 0.00 \\
\hline
\end{tabular}

\subsection{Optimization analysis}

The quality characteristic for machining is used by manufacturers because it affects the processing costs for the manufacturer and reliability for the consumer (or user). The geometric parameters for a forming tap for $f_{1}$ and $T_{1}$ are optimized using the two second-order models. It is easier to determine the thread filling rate than the minimum torque so the thread filling rate is used to optimize the quality characteristic to give a lower torque. The tool geometry $\left(W, D_{2}, D_{f}\right.$ and $\left.\theta\right)$ and 
tapping process parameters that are shown in Fig. 1 and Table 2 are used to optimize the thread filling rate. The optimal solution must satisfy the limiting condition for an objective function, which is:

$\left\{\begin{array}{c}\text { Objective function: } \operatorname{Min} T_{2 s} \\ \text { Limiting condition: } f_{2 s}-\mathrm{E}\left(f_{2 s}\right) \leq 0\end{array}\right.$

where $\mathrm{E}\left(f_{2 s}\right)$ is the expected thread filling rate, which is is $95 \%$. According to Eq. (5), the optimized thread filling rate $\left(f_{2 s}\right)$ must be less than or equal to $95 \%$. The coded variables for the optimal solution using MINITAB software are shown in Table 9. Table 9 shows that the code values for $W$ and $D_{f}$ are 1 and -1 , respectively. The larger the value of $W$, the smaller is the contact surface (or friction force) between the tool and the workpiece. Therefore, the smaller the contact surface between the tool and workpiece, the smaller is the tapping torque and the larger is the thread filling rate. The code values for $D_{2}$ and $\theta$ are -0.3279 and 0.3939 , respectively. If the code value for $D_{2}$ is -0.3279 the tapping torque decreases but this has little effect on the thread filling rate (T-value), as shown in Table 7, because the value for $\theta$ is the same.

Table 9 The optimal solution using the Box-Behnken design

\begin{tabular}{lcccc}
\hline & $\boldsymbol{W}$ & $\boldsymbol{D}_{\mathbf{2}}$ & $\boldsymbol{D}_{\boldsymbol{f}}$ & $\boldsymbol{\theta}$ \\
\hline Code & 1.0 & -0.3279 & -1.0 & 0.3939 \\
Variable & $(1.065 \mathrm{~mm})$ & $(0.9448 \mathrm{~mm})$ & $(0.9594 \mathrm{~mm})$ & $\left(60.96^{\circ}\right)$ \\
(Real value) & & & & \\
\hline
\end{tabular}

In order to verify the accuracy of the prediction model, the optimal solution is simulated using the finite element model and experiments. The error between the predicted, simulated and experimental conditions for the thread filling rate and the minimum torque is shown in Table 10 . Compared to the predicted condition, the respective error between the simulation and experimental conditions for the thread filling rate and minimum torque is $1.54 \%$ and $3.28 \%$ and $0.58 \%$ and $8.53 \%$. Fig. 12 shows the forming diagram for simulated tapping for the optimal solution using an effective stroke of $1.5 \mathrm{~mm}$. The result of Fig. 12(c) shows that the maximum stress on the FFT is distributed 
in the zone where the thread is formed. The modeling results agree well with practical experience in industry.

Table 10 The optimal solution for thread filling rate and the minimum torque

\begin{tabular}{ccccc}
\hline Condition & $\begin{array}{c}\text { Thread filling } \\
\text { rate }(\%)\end{array}$ & $\begin{array}{c}\text { Error } \\
(\%)\end{array}$ & $\begin{array}{c}\text { Minimum } \\
\text { torque (N-mm) }\end{array}$ & $\begin{array}{c}\text { Error } \\
(\%)\end{array}$ \\
\hline Prediction & 94.72 & - & 88.63 & - \\
Simulation & 93.26 & 1.54 & 88.12 & 0.58 \\
Examination & 91.61 & 3.28 & 81.07 & 8.53 \\
\hline
\end{tabular}



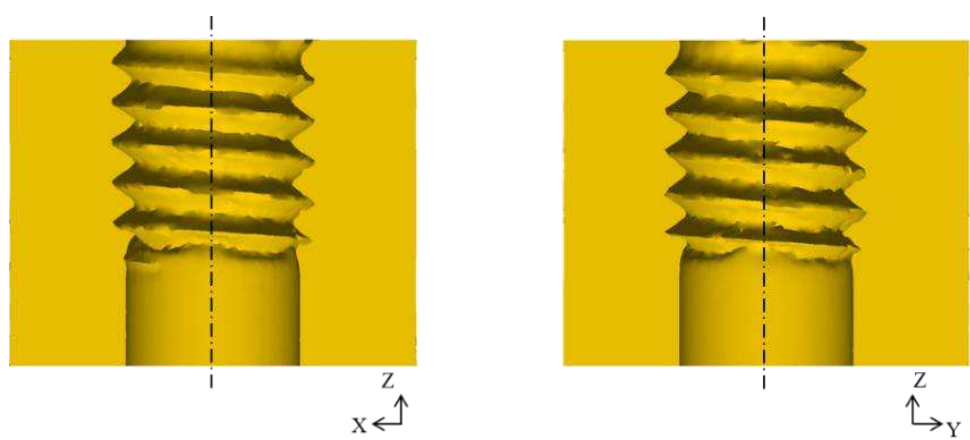

(a) Forming profile

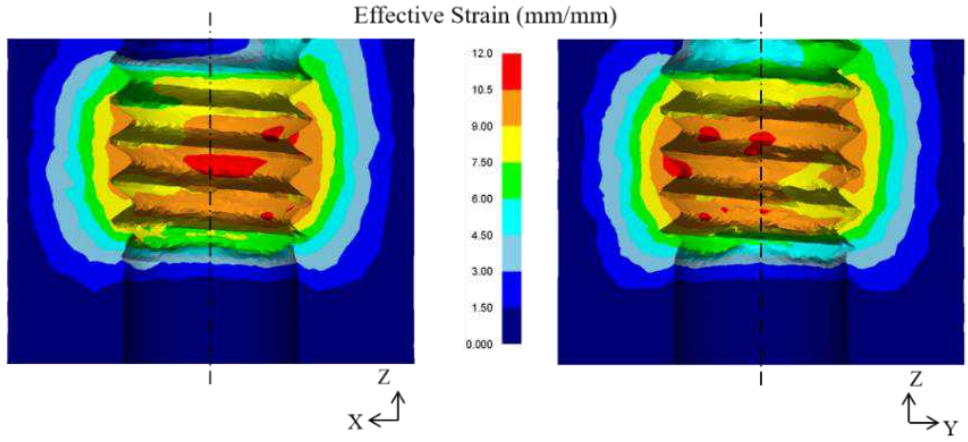

(b) Effective strain distribution

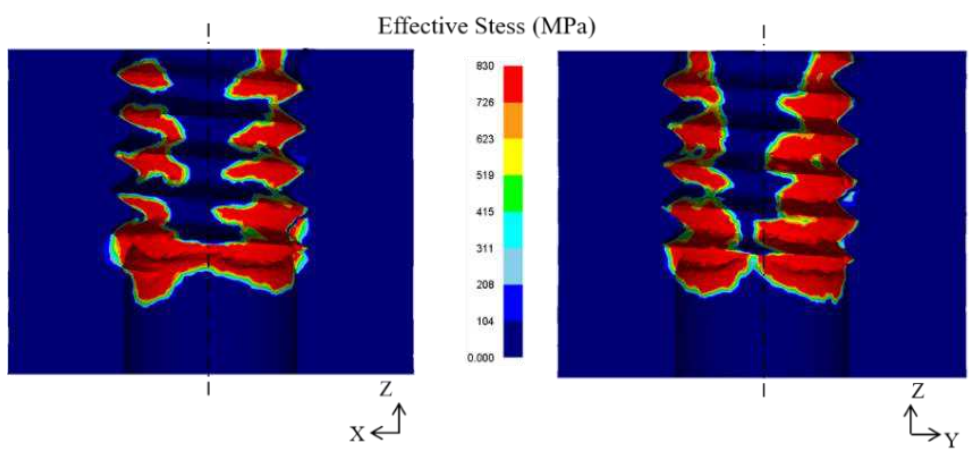

(c) Effective stress distribution

Fig. 12 The forming diagram for simulated tapping for the optimal solution using a stroke of 1.5

$\mathrm{mm}$

\section{Conclusion}

A Box-Behnken design (BBD) is an experimental method that is used in industry to solve an optimization problem with exact limitations. The use of a SBIT for $3 \mathrm{C}$ electronic products creates problems. A FFT is used to generate a SBIT because it produces fewer defects and results in a cheaper tapping process than a traditional tap. The tool geometric parameters $\left(W, D_{2}, D_{f}\right.$ and $\left.\theta\right)$ are optimized using DEFORM-3D and MINITAB software for a FFT to tap 7075-T6 aluminum alloy. The results allow the following conclusions to be drawn: 
1. The results of the ANOVA show that the determination coefficients $\left(R^{2}\right)$ for $f_{1}$ and $T_{1}$ are $97.0 \%$ and $90.6 \%$, so the two second-order models are significant. $W, D_{2}, D_{f}$ and $\theta$ are the parameters that affect the value of $f_{1}$ and $W, D_{2}$ and $\theta$ affect the value of $T_{1}$.

2. The difference between the predicted, the simulation and the experimental results is $0.5-9.0 \%$ in terms of the thread filling rate and the minimum torque. Using DEFORM-3D and MINITAB software, a small FFT is used to tap 7075-T6 aluminum alloy with acceptable results for the thread filling rate and the minimum torque.

3. The coded level for the explanatory variables using the optimal solution is $W=1.0, D_{2}=-0.3279$, $D_{f}=-1.0$ and $\theta=0.3939$. The simulation and examination results for the thread filling rate and the minimum torque are $93.26 \%$ and $91.61 \%$ and $88.12 \mathrm{~N}-\mathrm{mm}$ and $81.07 \mathrm{~N}-\mathrm{mm}$, respectively. In comparison to the prediction condition, the error for the simulation and the experiment is within acceptable limits, so the results for the simulation model and the experiment are a good fit to the Box-Behnken design.

Acknowledgements: The authors gratefully acknowledge the support of the Ministry of Science and Technology of the Republic of China, through Grant nos. MOST 108-2221-E-262-002-MY2.

Code availability: Not applicable.

Author contribution:

Ming-Chang Wu: Conceptualization, guided experimental process, data curation, characterization, validation, analysis, supervision, writing -review \& editing draft.

Wei-Rong Jian: Conducted the simulation, methodology, tapping experiments and writing-original draft, Ling-Sheng Hsu: Conducted the manufacture of forming tap.

Chung-Chen Tsao: Conceptualization, Project administration, Funding acquisition, revised some grammar.

All authors have read and agreed to the published version of the manuscript. 
Funding: The authors appreciate the financial support of the Ministry of Science and Technology of the Republic of China (MOST 108-2221-E-262-002-MY2).

Data availability: All necessary data is shown in the figures and Tables within the document. The raw data can be made available upon request

\section{Declarations:}

Ethical approval: Not applicable.

Consent to participate: Not applicable.

Consent to publish: Not applicable.

Conflict of interest: The authors declare no competing interests.

\section{References}

1. Chowdhary S, Ozdoganlar OB, Kapoor S, DeVor R (2002) Modeling and analysis of internal thread forming. Trans NAMRC/SME 30:329-336

2. Warrington C, Kapoor SG, DeVor RE (2005) Experimental investigation of thread formation in form tapping. J Manuf Sci Eng 127:829-836

3. Fromentin G, Poulachon G, Moisan A, Julien B, Giessler J (2005) Precision and surface integrity of threads obtained by form tapping. CIRP Ann- Manuf Technol 54:519-522

4. Fromentin G, Poulachon G, Moisan A (2006) An experimental and analytical method for investigating plastic flow in form tapping. Int J Forming Process 9:457-472

5. Pereira IC, Faria AE, Da Silva MB (2013) Influence of feed rate and threaded length in thread forming and tapping operations. Proc World Congr Eng (WCE 2013) 3, London, U.K

6. Oliveira J, Filho S, Brandão L (2019) Investigation of the influence of coating and the tapered entry in the internal forming tapping process. Int J Adv Manuf Technol 101:1051-1063

7. Warrington C, Kapoor SG, DeVor RE (2006) Finite element modeling for tap design improvement 
in form tapping. J Manuf Sci Eng 128: 65-73

8. Mathurin F, Guillot J, Stéphan P, Daidié A (2009) 3D finite element modeling of an assembly process with thread forming screw. J Manuf Sci Eng 131:151-158

9. Stéphan P, Mathurin F, Guillot J (2011) Analytical study of maximal tapping torque during forming screw process. J Mater Process Technol 211: 212-221

10. Huang XL, Li XF, Zuo DW, Miu H, Shi DB (2012) Effect of structural parameters of extrusion tap on torque during forming process of internal thread by cold extrusion. Tool Eng 10:18-22

11. Carvalho AO, Brandão LC, Panzera TH, Lauro CH (2012) Analysis of form threads using fluteless taps in cast magnesium alloy (AM60). J Mater Process Technol 212:1753-1760

12. Filho S, Oliveira J, Arruda E, Brandão L (2016) Analysis of burr formation in form tapping in 7075 aluminum alloy. Int J Adv Manuf Technol 84: 957-967

13 Tsao CC, Kuo KL (2012) Ultrasonic-assisted vibration tapping using taps with different coating. Trans Nonferrous Met Soc China 22:764-768

14. Chen ZZ, Li ZL, Niu JB, Zhu LM (2020) Chatter detection in milling processes using frequencydomain Rényi entropy. Int J Adv Manuf Technol 106:877-890 